\title{
Selected coelomic fluid parameters of sterlet, Acipenser ruthenus L.: effects of light color and photoperiod
}

\author{
Hajar Azarin, Mohammad Sadegh Aramli, Fatemeh Naderi
}

Received - 18 August 2014/Accepted - 25 November 2014. Published online: 31 December 2014; Inland Fisheries Institute in Olsztyn, Poland Citation: Azarin H., Aramli M.S., Naderi F. 2014 - Selected coelomic fluid parameters of sterlet, Acipenser ruthenus L.: effects of light color and photoperiod - Arch. Pol. Fish. 22: 243-247.

\begin{abstract}
Light and color have effect physiological aspects of fish such as growth, the neuro-hormonal system, and reproduction. In the present study, the effects of light color and photoperiod on the levels of selected parameters of coelomic fluid (glucose, total protein, cholesterol, calcium, magnesium) of female sterlet (Acipenser ruthenus) were investigated. Thirty-six broodstock were kept in 12 experimental tanks (500 l) for six months. The fish were reared under four different light regimes (two photoperiods of 18L:6D and 6L:18D and two colors - red and blue) at an intensity of $150 \mathrm{Lx}$ (three replicates). Fish reared under the red-long photoperiod had the highest concentration of the selected parameters of the coelomic fluid. Moreover, significant differences were noted in the all the parameters in fish reared under the red-long photoperiod in comparison with fish from the other treatments $(\mathrm{P}<0.05)$. The results indicate that light (color and photoperiod) influences egg quality during the final stage of $A$. ruthenus reproduction.
\end{abstract}

Keywords: light color, photoperiod, coelomic fluid, sterlet

H. Azarin

Department of Fisheries, Gorgan University of Agricultural Sciences and Natural Resources, Gorgan, Iran

M.S. Aramli ["”]

Department of Fisheries, Faculty of Natural Resources,

Urmia University, Urmia, Iran

e-mail: m.s.aramli@iauardabil.ac.ir; msaramli@gmail.com

F. Naderi

Department of Fisheries, Faculty of Natural

Resources, Guilan University, Sowmeh-Sara, Iran.

\section{Introduction}

Sturgeon stocks have declined because of overfishing for meat and caviar production, habitat destruction, and environmental pollution (Billard and Lecointre 2001). Therefore, most species of acipenserids are listed as endangered by IUCN (2012). Sterlet, Acipenser ruthenus L., is the smallest sturgeon and is considered to be the most suitable species for biological, nutritional, and genetic studies because of higher early growth rates and earlier maturation compared with other sturgeon species (Sokolov and Vasiliev 1989). Light rays of different wavelengths pass through water to different depths depending on light absorption, diffusion, and the water content of admixtures and small organisms. Most species of fish have well-developed color sight, and are therefore very sensitive to colored light (Ruchin 2004). Photoperiod is classified as a directive and abiotic factor that can affect the growth performance of aquatic organisms by influencing the endocrine system. Photoperiod manipulation has been used successfully to improve the growth and reproduction of a number of teleost fishes. Additionally, photoperiod affects the hypothalamus-pituitary-internal axis (HPI) and is one of the main environmental cues for reproduction timing. Since illumination can affect the reproductive performance of fish, it is probable that light regime changes during the final 
reproduction stages and near the time of spawning could affect broodfish breeding and spawning (Craig 2000, Borg 1994, Fontaine et al. 2006, Falahatkar et al. 2012).

The effects of colored light and photoperiod on various aspects of fish physiology have been investigated, including growth, survival, the neuro-hormonal system, reproduction, behavior, and the stress response (Volpato and Barreto 2001, Bayarri et al. 2002, Naor et al. 2003, Ruchin 2004, Karakatsouli et al. 2007, Bani et al. 2009, Banan et al. 2011, Pourhosein Sarameh et al. 2012). However, data regarding the effect of colored light and photoperiod on A. ruthenus broodstocks in the final stage of reproduction are scarce. Therefore, the aim of this study was to examine $A$. ruthenus coelomic fluid parameters to detect changes in glucose, total protein cholesterol, and ionic content $\left(\mathrm{Ca}^{2+}\right.$ and $\left.\mathrm{Mg}^{2+}\right)$ in broodstocks that were subjected to photomanipulation during the final stage of reproduction.

\section{Materials and methods}

\section{Fish and experimental condition}

This study was performed during a six-month period from November 2011 to April 2012 in at the International Sturgeon Research Institute in Rasht, Guilan, Iran. The fish $(\mathrm{n}=36)$ were held in 12 square $(100 \times 100 \times 42 \mathrm{~cm})$ fiberglass tanks (rearing volume -500 l) during an acclimatization period of five days. Data on initial fish length and weight are presented in Table 1 . The fish were fed manually twice daily with a commercial diet (ALLER AQUA, Denmark) during the adaptation period and throughout the experiment. The dry matter content of the diet was $87.8 \%$ and comprised $40.1 \%$ crude protein, $19.6 \%$ crude fat and $5.62 \%$ crude ash. All tanks received equal amounts of food at each feeding time. The experimental tanks were cleaned (siphoned) every morning before the first feeding. Water temperature, oxygen content, and $\mathrm{pH}$ were $16-18^{\circ} \mathrm{C},>5.3 \mathrm{mg} \mathrm{l}^{-1}$, and 7.1-7.5, respectively, during the experiments.
Table 1

Sterlet (A. ruthenus) female sizes and weights in the test tanks under different colored light and photoperiod treatments

\begin{tabular}{llll}
\hline \hline Treatment & $\mathrm{n}$ & $\begin{array}{l}\text { Body weight } \\
(\mathrm{g})\end{array}$ & $\begin{array}{l}\text { Total length } \\
(\mathrm{cm})\end{array}$ \\
\hline \hline 6L:18D: red & 9 & $557.6 \pm 144$ & $50.55 \pm 2.18$ \\
18L:6D: red & 9 & $730.4 \pm 29.61$ & $54 \pm 1.8$ \\
6L:18D: blue & 9 & $678.2 \pm 58.45$ & $52.44 \pm 3.24$ \\
18L:6D: blue & 9 & $701.4 \pm 8.77$ & $51.61 \pm 1.11$ \\
\hline \hline
\end{tabular}

\section{Experimental design}

The 12 tanks were assigned randomly to one of the four experimental treatments (three replicates per treatment) to assess the effects of the various photoperiods studied. All the tanks were separated by black plastic sheets and were illuminated with energy-saving tube lamps (Novin Light Co., Karaj, Iran). Four different photoperiods were established: two light colors (red and blue) and two light regimes (18L:6D and 6L:18D). The light was controlled by a light meter (LI-COR, model Li-1776, Lincoln, NE, USA). The light intensity at the surface of each tank in all treatments was adjusted to $150 \mathrm{~lx}$.

\section{Sampling protocol and measurements}

To estimate the stage of germinal vesicle (GV) migration before spawning, 20-30 oocytes were collected, boiled for $5 \mathrm{~min}$, and bisected from the vegetable pole (VP) to the animal pole (AP) to measure the distances from the VP to the AP and from the AP to the nucleus under a dissecting microscope.

Fish were sampled after being anesthetized in a buffered solution of tricaine methane sulphonate (MS 222), which induced the cessation of body and opercular movements within 4-8 minutes after exposure. Coelomic fluid and ovulated oocytes were obtained from females and deposited onto meshed textile. The coelomic fluid was then withdrawn with a syringe and transferred into micro tubes. Samples were frozen immediately and stored at $-20^{\circ} \mathrm{C}$ until 
further processing. The concentrations of magnesium and calcium were measured with the colorimetric procedure in an Autoanalyser Technican (RA 1000, Technican, Swords, Dublin, Ireland). The coelomic fluid biochemical constituents were analyzed using an auto analyzer (Eurolyser, Detect 1970) and commercial clinical investigation kits (Pars Azmoon kit, Tehran, Iran). Biochemical measurements were performed for total protein, glucose, and cholesterol. Ionic and organic compositions were measured three times per sample.

\section{Statistical analyses}

Statistical analysis was conducted using SPSS (Version11.5, SPSS Chicago, IL, USA), and differences of $\mathrm{P}<0.05$ were considered to be statistically significant. The data were analyzed with two-way analysis of variance (ANOVA). Duncan's test was used to identify significant differences among the various means. The values are presented as means \pm SD.

\section{Results and discussion}

The results of the different color and light regimes on the mean values of coelomic fluid parameters are presented in Fig. 1a-e. The fish reared under a red-long photoperiod had the highest concentration of glucose, total protein, cholesterol, calcium, and magnesium. In addition, there were significant differences in the all the selected parameters of fish reared under a red-long photoperiod in comparison to the other treatments $(\mathrm{P}<0.05)$. In sturgeon, as well as in other teleosts, an increase in glucose level is considered a secondary indicator of the stress response (Barton et al. 2000, Belanger et al. 2001). The other parameters measured in our study were also likely to change in response to stress or environmental variations. Changes in day length and light regime were involved in secondary stress responses in sterlet. Furthermore, ion concentrations were affected by changing light regimes. Our results are in good agreement with previous observations of
Askarian et al. (2008) in beluga, Huso huso (L.). The results of another study by Volpato and Barreto (2001) reinforce the idea that colored light affects the HPI axis and, consequently, it may influence various biological systems. It should be emphasized that assessing fish welfare would also require measuring cortisol and glucose, which are the main end products of the HPI axis and a secondary indicator of stress response, respectively (Barcellos et al. 2009). It seems that female sterlet brooders are sensitive to light and finally react to constant light with an increased glucose level as a stress response. Because stress responses might change under different photoperiods, light regimes may cause higher or lower sensitivity (Biswas et al. 2006). Additionally, the exposure time of the stressor can influence the magnitude of physiological responses and the sensitivity of the physiological response depends on stressor type (Acerete et al. 2004). Thus, our results suggest that female sterlet are sensitive to long day light in the final stages of reproduction. The effect of photoperiod on egg quality is difficult to study, because manipulation of photoperiod often results in the modification of other parameters throughout oogenesis, including those during late oogenesis (Bobe and Labbe 2010). Moreover, available data indicate that photoperiod-induced manipulation of spawning data can impact egg quality. The importance of this effect on egg quality seems highly dependent on the type of photoperiod regime used. To conclude, the sensitivity of coelomic fluid parameters of sterlet brooders to constant photoperiods in this reproductive stage is indicated here, and the effects of the intensity, duration, and time of applying stressors in different reproductive stages on physiological responses are taken into account. More research is necessary to foster a complete understanding of these effects and sensitivities. The results obtained here along with those of future studies might help to develop a suitable photoperiod regime or to change photoperiods in different stages of maturity until the spawning of sterlet. Furthermore, it is necessary to conduct studies on the effects of photoperiod on altering the timing of maturation and various 

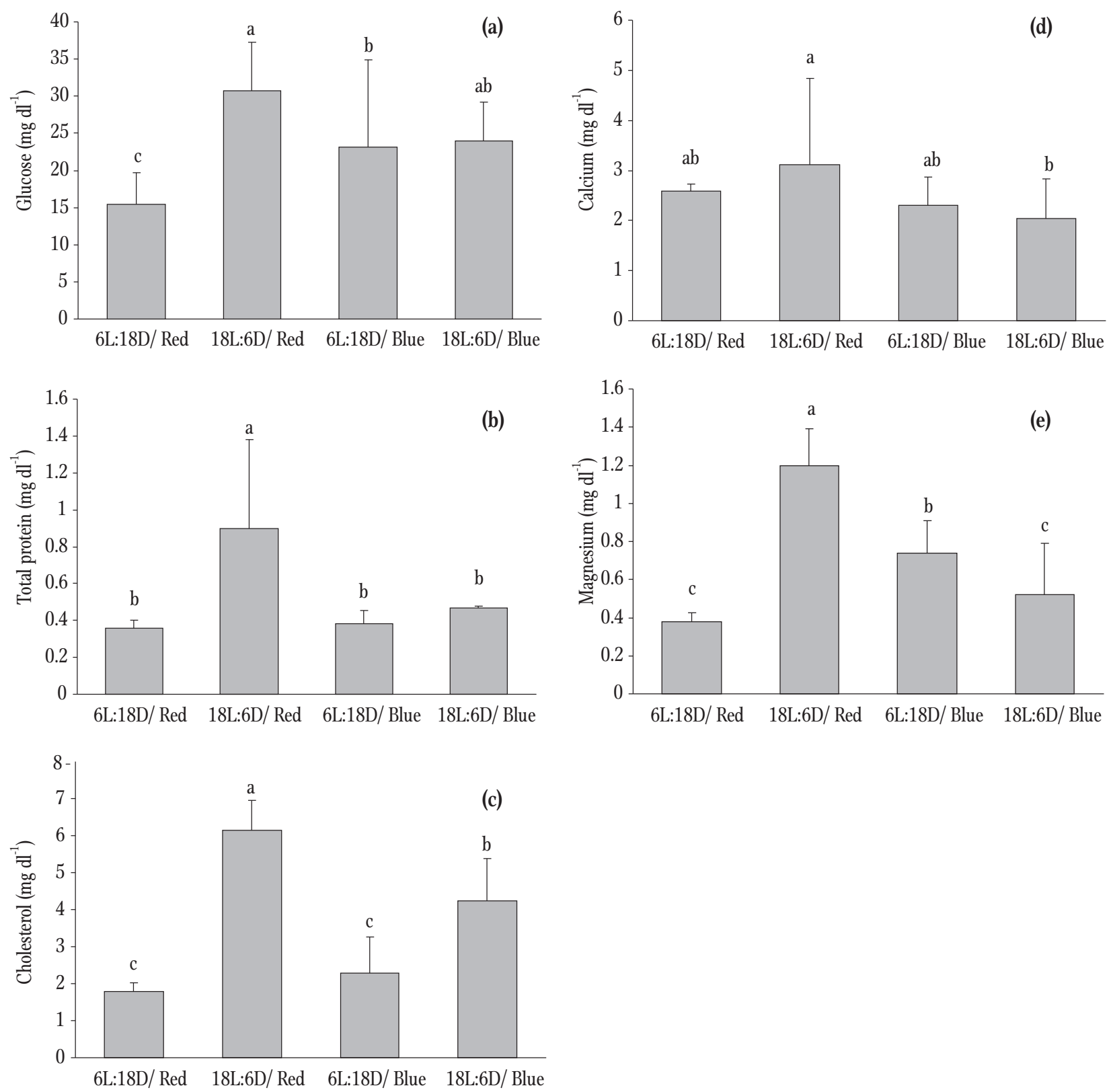

Figure 1. Mean values $( \pm$ SD) of selected coelomic fluid parameters: glucose (a), total protein (b), cholesterol (c), calcium (d), and magnesium (e) of female starlet (A. ruthenus) broodstocks reared under different colored light and photoperiod treatments.

maturational processes, and the effects of light intensity, duration, and different photoperiod applications during different reproductive stages of sterlet on serum parameters, the immune system, the stress response, and reproductive performance.

Author contributions. H.A. and F.N. designed and performed the experiment; H.A. analyzed the data, M.S.A. wrote the manuscript.

\section{References}

Acerete L., Balasch J.C., Espinosa E., Josa A., Tort L. 2004 Physiological responses in Eurasian Perch (Perca fluviatilis L) subjected to stress by transport and handling - Aquaculture 237: 167-178.

Askarian F., Kousham A., Bahmani M. 2008 - Serum parameters of beluga sturgeon, Huso huso (Pisces: Acipenseriformes): Effect of different light regimes World Aquacult 39: 6-8. 
Banan A., Kalbassi M.R., Bahmani M., Sadati M.A.Y. 2011 Effects of colored light and tank color on growth indices and some physiologicalparameters of juvenile beluga (Huso huso) - J. Appl. Ichthyol. 27: 565-570.

Bani A., Tabarsa M., Falahatkar B., Banan A. 2009 - Effects of different photoperiods on growth, stress and haematological parameters in juvenile great sturgeon, Huso huso - Aquacult. Res. 40: 1899-1907.

Barcellos L.J.G., Kreutz L.C., Quevedo R.M., da Rosa J.G.S., Centenaro G.K.L., Pottker E. 2009 - Influence of color background and shelter availability on Silver catfish (Rhamdia quelen) stress response - Aquaculture 288: 51-56.

Barton B.A., Bolling H., Hauskins B.L., Jansen C.R.J. 2000 Juvenile Pallid (Scaphirhychus albus) and hybrid Pallid $\times$ shovelnose (S. albus $\times$ platorynchus) sturgeons exhibit low physiological responses to acute handling and severe confinement - Comp. Biochem. Physiol. 126: 125-134.

Bayarri M.J., Madrid J.A., Sanchez-Vazquez F.J. 2002 Influence of light intensity, spectrum and orientation on sea bass plasma and ocular melatonin - J. Pineal. Res. 32: 34-40.

Belanger J.M., Son J.H., Laugero K.D., Moberg G.P., Dorochov S.I., Lankford S.E., Cech J.J. 2001- Effects of Short-term management stress and ACTH injections on plasma cortisol levels in cultured white sturgeon, Acipenser transmontanus - Aquaculture 203: 165-176.

Billard R., Lecointre G. 2001- Biology and conservation of sturgeon and paddlefish - Rev. Fish Biol. Fish. 10: 355-392.

Biswas A.K., Seoka M., Tanaka Y., Takii K., Kumai H. 2006 Effect of photoperiod manipulation on the growth performanceand stress response of juvenile red sea bream Pagrus major - Aquaculture 258: 350-356.

Bobe J., Labbe C. 2010 - Egg and sperm quality in fish - Gen. Comp. Endocrinol. 165: 535-548.

Borg B. 1994 - Androgens in teleost fishes - Comp. Biochem. Physiol. 109C: 219-245.
Craig J.F. 2000 - Percid Fishes: Systematics, Ecology and Exploitation - Fish and Aquatic Resources Series.vol. 3. Blackwell Science: $352 \mathrm{p}$.

Falahatkar B., Poursaeid S., Efatpanah I., Meknatkhah B., Biswas A. 2012 - Effect of photoperiod manipulation on growth performance, physiological and hematological indices in juvenile Persian sturgeon, Acipenser persicus J. World. Aquac. Soc. 43: 692-700.

Fontaine P., Pereira C., Wang N., Marie M. 2006 - Influence of pre inductive photoperiod variations on Eurasian perch, Perca fluviatilis broodstock response to an inductive photothermal program - Aquaculture 255: 410-416.

Karakatsouli N., Papoutsoglou S.E., Pizzonia G.,Tsatsos G.,Tsopelakos A., Chadio S., Kalogiannis D., Dalla C., Polissidis A., Papadopoulou-Daifoti Z. 2007 - Effects of light spectrum on growth and physiological status of gilthead seabream, Sparus aurata and rainbow trout, Oncorhynchus mykiss reared under recirculating system conditions - Aquacult. Eng. 36: 302-309.

Naor A., Segev N., Bressler K., Peduel A., Hadas E., Ron B. 2003 -The influence of the pineal organ and melatonin on the reproductive system and of light intensity and wavelength on melatonin in the Gilthead Sea bream (Sparusaurata) - Isr. J. Aquacult. 55: 230.

Pourhosein Sarameh S., Falahatkar B., AzariTakami G., Efatpanah I. 2012 - Effects of different photoperiods and handling stress on spawning and reproductive performance of pikeperch, Sander lucioperca - Anim. Reprod. Sci. 132: 213-222.

Ruchin A.B. 2004 - Influence of colored light on growth rate of juveniles of fish - Fish. Physiol. Biochem. 30: 175-178.

Sokolov L.I., Vasiliev V.P. 1989 - Acipenser ruthenus Linnaeus - In: The freshwater fishes of Europe, (Ed.) Holcik J. AULA-Verlag, Wiesbaden: 227-262.

Volpato G.L., Barreto R.E. 2001- Environmental blue light prevents stress in the Nile tilapia - Braz. J. Med. Biol. Res. 34: 1041-1045. 